\title{
A mobilidade social na sociedade de Antigo Regime*
}

António Manuel Hespanha*

Embora não se encontre, na Época Moderna, referência à “mobilidade social”, ela era possível e provinha de poderes extraordinários, como o do rei, que emancipa, legitima, enobrece. Qual é a mobilidade possível e legítima? Quais são os mecanismos de mudança? Quais os riscos? Quais os títulos de prova? As respostas a estas perguntas, sobre as quais se constroem estratégias de vida, provêm de um universo de representações que este artigo se propõe a descrever genericamente.

Palavras-chave: Antigo Regime - Mobilidade social - Direito

\section{Social Mobility in the Ancien Régime Society}

Although one cannot find, in Modern Age, reference to "social mobility", this was a possibility and had origins in extraordinary powers, such as those exercised by the king, which enabled him to emancipate, to legitimize, to turn into noble. Which wass the possible and lawful mobility? Which were the change mechanisms? Which were the risks? Which were the proof titles? The answers to these questions, upon which one build up his/her life strategies, come from a representation universe that this article proposes to describe in general terms.

Keywords: Ancien Régime - Social mobility - Law

\section{La mobilité sociale dans la société de l'Ancien Régime}

Bien qu'à l'époque moderne on ne trouve pas de références à la "mobilité sociale", elle était possible et trouvait son origine dans des pouvoirs extraordinaires, notamment celui du roi, qui pouvait accorder l'émancipation, la légitimation, l'anoblissement.

\footnotetext{
"Artigo recebido em janeiro de 2006 e aprovado para publicação em abril de 2006.

${ }^{* *}$ Professor Catedrático no Departamento de Direito da Universidade Nova de Lisboa. Email: amh@uniduo.pt.
} 
Quelle mobilité était possible et légitime? Quels sont les mécanismes de changement? Quels sont les risques? Quelles sont les difficultés? Les réponses à ces questions - sur lesquelles des stratégies de vie sont construites - se trouvent dans l'univers des représentations, que cet article propose de décrire de façon générale.

Mots-clefs: Ancien Régime - Mobilité sociale - Droit

\section{Introdução}

O tema da mobilidade social é, do ponto de vista histórico, um destes temas equívocos que, por parecerem que são de sempre, ocultam facilmente o fato de ser, sobretudo, de hoje.

Não creio ter encontrado nunca, numa fonte histórica da Época Moderna, uma referência à "mobilidade social". Pelo menos, nunca a encontrei com este sentido atual de algo de natural ou, menos ainda, de benéfico.

Alguma mobilidade começava, desde logo, por ser impossível. Não se podia deixar de ser mulher, por exemplo. Demente era também um estado tendencialmente definitivo. Menor, deixava-se naturalmente de se ser, mas pela passagem objetiva e natural do tempo, a menos que interviesse algo de extraordinário, como a graça real da emancipação. Selvagens e rústicos podiam, relativamente, aperfeiçoar-se. Mas os progressos eram problemáticos e lentos, ligados a um êxito educativo mais longo e mais incerto do que o das crianças. Menos definitivo era o estado de mecânico ou de pobre. Mas, mesmo nestes casos, a mudança tinha que respeitar ritmos e passos que não dependiam senão em muito pouco da vontade própria. Não quero com isto dizer que a situação (econômica, social, cultural) das pessoas não mudasse, para melhor ou para pior. Quero antes sugerir que isto: a) quase não se via; b) pouco se esperava; c) e mal se desejava.

Desde logo, quase não se "viam" - no sentido de que não tinham relevo social maior - algumas mudanças que hoje são, pelo contrário, evidentes. Por exemplo, as mudanças na fortuna. Como veremos, enriquecer ou empobrecer não era um fato social decisivo, do ponto de vista da categorização. A figura do nobre empobrecido, mas apesar disto nobre, ou do burguês enriquecido, mas todavia burguês, são características da literatura moral ou pícara das sociedades modernas, sobretudo na Europa do Sul. Como veremos adiante, a riqueza não é, em si mesma, um fator decisivo de mudança social. 
Outras mudanças produziam-se num tempo tão largo que se tornavam invisíveis. Tal é o caso da ascensão social paulatina, em que só se pode testemunhar a situação presente, ficando a situação anterior tão longe no passado, que a memória já nem sequer a pode registrar (quae memoria non exstat). Admite-se que terá havido uma mudança, mas a posse de estado é tão antiga, tão arraigada (radicata), que a mudança mais se presume do que se nota.

Em contrapartida, da mudança rápida e notória, o menos que se pode dizer é que não é de esperar. É como que um milagre. E, como fato extraordinário, tem que provir de poderes extraordinários, como o poder do rei, que, por rescrito, emancipa, legitima, enobrece. As formalidades destes atos denotam o seu caráter ímpar e fora do normal curso das coisas humanas. São como sacramentos temporais, em que a intervenção suprema muda a natureza das pessoas. No plano espiritual, correspondem-lhe os outros sacramentos que, eles também, modificam os estados. O batismo, que abre o estado de cristão; o matrimônio, que cria o estado de casado; a ordem, que inaugura o estado clerical; a extrema unção, que prepara o fim de todos os estados.

A mudança rápida não se espera e, em geral, tão pouco se deseja. Mudança e confusão de estados são, para o homem moderno, sinais de perturbação social e de convulsão da ordem política. Sinais, como diz alguma fonte, de tempos "muito voluntários", ou seja, de tempos em que os golpes da vontade (do rei, dos particulares) tendem a sobrepor-se ao objetivo e ao praeter-voluntário curso do mundo.

É a partir desta cultura de base do homem moderno que a "mobilidade social” tem que ser estudada. Qual é a mobilidade possível e legítima? Quais são os mecanismos ou as vias legítimas de mudança? Quais os tempos? Quais os riscos? Quais os títulos de prova? As respostas a estas perguntas, sobre as quais se constroem estratégias de vida, estão implícitas num universo de crenças e pré-compreensões que aqui trataremos de descrever genericamente.

Sem o conhecimento deste código moral, a interpretação das mutações no universo social moderno resulta muito problemática. Dramatizando um pouco a afirmação, diria que os fatos brutos - de que um enriqueceu, de que outro se tornou nobre, de que um terceiro doou os seus bens e entrou em religião - em si mesmos, sem esta referência a um código específico (ou local) de avaliações de atos e de situações, são inúteis, no plano da interpretação histórica. Explico. Se se quiser compreender o significado destes fatos para os homens da época - e, assim, entender as suas ações ou reações relativamente 
à mudança social -, temos que recuperar os quadros mentais dentro dos quais a mutação social encaixa e cobra sentido. Sem isto, ou nos limitamos a narrar fatos sem sentido ou - o mais freqüente - imputamo-lhes implicitamente os sentidos que têm hoje em dia.

\section{Ordem evontade-Um mundo relativamente indisponível}

Num passo central da Summa theologica, S. Tomás de Aquino coloca uma perturbante questão sobre a eficácia da vontade criadora de Deus. Escreve ele, formulando o paradoxo que lhe serve de ponto de partida:

A justiça é dar o devido, a misericórdia é remediar a miséria. E, assim, tanto a justiça como a misericórdia pressupõem algo de prévio [um padrão, uma ordem] para operar. A criação, por sua vez, não pressupõe nada. Por isso, na criação não há nem justiça nem misericórdia. Porém, contra isto, diz o Salmo (Ps., 24,10): todas as estradas do Senhor são de misericórdia e de verdade. ${ }^{1}$

Aqui, o elemento paradoxal está no fato de que, se atribuímos a Deus uma plena liberdade de instituição da ordem do mundo, renunciamos a fundar esta ordem na justiça ou na misericórdia. Se estabelecemos que estas duas virtudes estão na própria raiz das coisas, então negamos ao ato instituidor de Deus a natureza gratuita e criadora.

A solução dada por $\mathrm{S}$. Tomás é a de submeter o ato criador a um plano devido, preexistente na sapiência e na bondade de Deus. A graça original cria o mundo segundo um plano inteligente e racional. E, neste sentido, participa da justiça. Os atos subseqüentes de graça e de misericórdia continuam a participar da justiça, na medida em que, longe de representarem atos arbitrários, aperfeiçoam ainda mais a justiça: "Deus atua misericordiosamente não contra a justiça, mas operando para além da justiça (...) pelo que não suprime a justiça, mas institui a plenitude da justiça", ${ }^{2}$ ou seja, a justiça (o equilíbrio) do mundo é uma característica permanente e que se impõe sempre à vontade. Ainda que esta, atuando extraordinariamente (como que por milagre), possa aperfeiçoar a ordem atual, em vista, no entanto, de uma ordem virtual ainda mais perfeita.

\footnotetext{
${ }^{1}$ Santo Tomás, Summa theol., 2-2, q. 30, a.1.

${ }^{2}$ Idem, I, q. 31, a.
} 
No final, o que se está a discutir é o modelo de relações entre justiça, graça e misericórdia, questão que, sendo central na teologia, o é também na teoria dos atos humanos, maxime dos atos de governo. E, muito concretamente, nesta questão de saber como podem os homens mudar a ordem social e mover-se nela.

São estes, portanto, os marcos que determinam o imaginário dos processos de mudança social.

\section{Oequilíbrio}

\section{Honestidade}

A mudança de situação na sociedade é, antes de tudo, um processo natural, como a mobilidade das estações do ano, a gestação dos seres vivos, a corrupção ou a revolução das coisas. Por isso, tem os seus processos e trâmites devidos, produz efeitos também devidos e esperados, tem os seus tempos e ritmos, sobretudo, exige uma duração que lhe permita "ganhar naturalidade".

O conceito central aqui é o de honestidade. A honestidade é a virtude que procura o bem racional (bonum rationale); e que, por isso, tem como raiz a regra da razão. ${ }^{3}$ Daí que o honesto se relacione com a "disposição perfeita e ótima”, ${ }^{4}$ lição que já vem de Aristóteles. Não admira pois que o honeste vivere, considerado como um dos preceitos do direito, ${ }^{5}$ seja o viver de acordo com os preceitos da natureza. ${ }^{6}$

Ainda segundo o filósofo, o honesto está intimamente ligado à honra e esta à hierarquia natural das coisas e à reação que esta deve suscitar. "O honesto - escreve São Tomás ${ }^{7}$ - importa débito de honra. Mas a honra é a reação adequada à excelência de alguém”. Assim, a prestação das honras devidas é a atitude de quem mantém uma postura honesta. Esta atitude, ainda que interior, tem manifestações exteriores, como a conversação. De onde a conversação honesta é a que traduz adequadamente, nos seus termos, nos seus temas e nas suas fórmulas, a relação justa (ajustada) entre os conversadores.

\footnotetext{
${ }^{3}$ Ibid, 2-1, q. 39, 2, ad. 1.

${ }^{4}$ Ibidem, 2-2, q. 145 , a. 1.

${ }^{5}$ Ulpiano, Digesto, D., 1,1,10,2.

${ }^{6}$ Bento Gil, Tractatus de jure, et privilegiis honestatis in duo diviginti articulos distributus quibus universum pertinet, explicatur, Olyssipone, apud Petrum Craesbeck, 1618, maxime art. 6.

${ }^{7}$ Santo Tomás, op. cit, 2-2, q. 145, 1.
} 
Também é grande a proximidade entre honestidade e beleza (decus), já que uma e outra indicam proporção justa.

A beleza do corpo consiste em que o homem tenha os membros do corpo bem proporcionados, com aquela claridade das cores devidas. E, correspondentemente, a beleza espiritual consiste em que a sua conversação ou os seus atos sejam bem proporcionados segundo a claridade espiritual da razão. Mas isto pertence à razão do honesto que, como dissemos, é a virtude que modera todas as coisas humanas segundo a razão. ${ }^{8}$

Já se vê que no pólo oposto à honestidade está o falso, o artificial, o desordenado ou disforme.

Honesto deve ser, por exemplo, o uso do matrimônio. Justamente porque se enraizava na natureza, o matrimônio devia ter um uso honesto; ou seja, devia consistir em práticas (maxime sexuais) das quais a forma, a ocasião, o lugar e a freqüência não dependiam do arbítrio ou do desejo dos cônjuges, mas de imperativos naturais. Numa palavra, das finalidades naturais e sobrenaturais do casamento: a) procriação e educação da prole; b) mútua fidelidade e sociedade nas coisas domésticas; c) comunhão espiritual dos cônjuges; e d) - objetivo conseqüente à queda do gênero humano, pelo pecado original - o remédio contra a concupiscência. ${ }^{9}$

Honestas devem ser as viúvas. São-no as que observam as regras de viver aceitas como próprias (pudicitia vidualis), evitando hábitos e ornatos impróprios de viúvas, assim como as conversas ociosas e o trato com homens desonestos. ${ }^{10}$ Ainda que o habitus non facit viduas ${ }^{11}$ (aut monacus), o qualificativo de "honesto" acompanha freqüentemente a referência ao traje. É que "os vestidos manifestam a qualidade da pessoa e provocam o respeito", ${ }^{12}$ de onde as pessoas honestas se devam acomodar ao que os usos do lugar determinam para cada categoria de pessoa. ${ }^{13}$

O mesmo se diga das ocupações e das profissões. Os mecânicos, por exemplo - categoria em que se incluem profissões tão diversas como ourives,

\footnotetext{
${ }^{8}$ Idem, 2-2, q. 145, a. 2.

${ }^{9}$ Cf. supra.

${ }^{10}$ Cf., v.g., Manuel Alvares Pegas, Commentaria in Ordinationes Regni Portugalliae, tom. VII, Ulysipone 1682, p. $243, \mathrm{n}^{\text {os }} 11$ ss.

${ }^{11}$ Idem, $\mathrm{n}^{\circ} 12$.

${ }^{12}$ Ibid., p. 250, n 10.

${ }^{13}$ Cf., v.g., Partidas, II, 18.
} 
regatões, carniceiros, barbeiros, caldeireiros, tendeiros, moleiros, tecedores, alfaiates, pescadores e marinheiros, pintores, chapeleiros -, estão impedidos por uma honestidade que se transmuta freqüentemente em regras de direito de se intrometerem em profissões não mecânicas, mas inclusivamente de assumir profissões mecânicas alheias.

É adequado - escreve Pegas, citando outra autoridade - responsabilizar o alfaiate que se intrometa em seara alheia. E parece que não apenas relativamente a ministérios eclesiásticos, mas também na esfera dos mesmos ofícios mecânicos. Entre os quais, um não pode meter-se em o do outro. Por exemplo, o de semeador, ou de fabricante ou outro, devendo ser coimados caso o façam (...) Tampouco pode um ofício assumir a insígnia ou sinal de outro (...) A origem destas interdições é evitar que se perturbem os ofícios e se dissolva no caos o governo político (...) do mesmo modo, não é justo que alguém se ocupe [publicamente, com tenda aberta] de diversos ofícios, pois desta mistura de ofícios se seguiria a confusão e a desordem na República. ${ }^{14}$

Este uso honesto dos ofícios aconselha também que cada um siga os dos seus pais, "pois normalmente os filhos costumam imitar os pais, de modo que são mais inclinados para artes que os pais exercem". ${ }^{15}$ Como refere Camões, descrevendo os usos dos indianos de Calicute:

Porque os que usaram sempre um mesmo ofício,

De outro não podem receber consorte,

Nem os filhos terão outro exercício,

Senão os de seus pais até à morte. ${ }^{16}$

Interessante é ainda a relação da honestidade com as riquezas.

São conhecidos os tópicos anticrematistas da tradição evangélica. ${ }^{17} \mathrm{~A}$ acumulação de bens é aí freqüentemente posta sob suspeita de imoralidade. Nas comunidades camponesas, de economia fechada, os bens servem necessidades de gozo, não de acumulação; exceção feita para a acumulação natural - v.g., para semente ou para prover infortúnios, próprios ou alheios, futuros e imprevisíveis (más colheitas, doenças). Ainda mais longínqua de uma vida

${ }^{14}$ Idem, VII, p. 256, 1-2.

${ }^{15}$ Ibid., p. 257, 5.

${ }^{16}$ Camões, Lusíadas, VIII, 38.

${ }^{17}$ Para os lugares comuns sobre riqueza e pobreza na tradição literária da época moderna, v., por todos, Joseph Langio, Florilegii magni, seu Polyantheaefloribus novissimis sparsae, Lugduni, 1631, s.v. "Divitiae", "Paupertas". 
natural é a acumulação de bens que não servem necessidades diretas ou naturais, como é o caso dos metais preciosos ou da moeda. Se buscar a pletora de bens naturais (frutos, gado, terra), já é problemático desde o ponto de vista de uma economia natural, muito mais o é a acumulação de bens que, por si mesmos, não matam a fome nem vestem o corpo. ${ }^{18} \mathrm{~A}$ esta diferença se refere S. Tomás, quando distingue a riqueza moderada e natural (divitiae naturales [panem et vinum]), da riqueza artificial (divitiae artificiales [pecuniae]). ${ }^{19}$

Além disto, a aquisição da riqueza tem os seus trâmites e os seus tempos. Não deve ser buscada por si, mas constituir o resultado de uma gestão prudente do seu. Não deve ser conseguida à custa da liberalidade ou da caridade. $\mathrm{E}$, com isto, leva tempo a ser conseguida. Riqueza rápida é sinal de ambição ilegítima ou de conduta desonesta.

A distinção fundamental em matéria de riqueza é, então, esta, que separa a riqueza honesta, pelos seus fins e pelos seus meios, da desonesta. A riqueza honesta é a obtida por meios justos e para fins justos. É, sobretudo, a riqueza antiga, já incorporada nos equilíbrios da sociedade. Quando conforme a este padrão de aquisição, a riqueza pode inclusivamente denotar virtudes, como a da prudência, da frugalidade ou da modéstia e, neste sentido, testemunha o agrado de Deus. A esta riqueza se refere o mesmo S. Tomás, quando diz que "segundo a opinião vulgar, a excelência das riquezas faz o homem digno de honra, sendo por isso que, algumas vezes, a palavra honestidade se aplica à prosperidade exterior", ${ }^{20}$ ou os juristas, quando afirmam que a riqueza induz nobreza. ${ }^{21}$

A riqueza é, portanto, ambivalente na sua valoração. Mas mesmo a honesta também resulta equívoca nas suas conseqüências morais.

Por uma parte, está cheia de perigos, ao criar o risco contínuo de esquecimento da ordem natural e das suas exigências. Assim, suscita a glória vã, i.e., uma glória não justificada, artificial, não natural. Cria o amor perverso (desordenado) pela própria riqueza. E, finalmente, gera um estado de contínua solicitude e atenção que prejudica o cuidado com a justiça e com a caridade (ou seja, com as virtudes que mantêm a ordem). ${ }^{22}$

\footnotetext{
$\overline{{ }^{18} \text { As imagens negativas sobre o comércio arrancam também desta suspeita sobre a busca }}$ directa da riqueza, maxime, monetária.

${ }^{19}$ Santo Tomás, op. cit., 2-2, q. 188, ad. 5.

${ }^{20}$ Idem, 2-2, q. 145, a1 ade. 4.

${ }^{21}$ Cf., v.g., M. A. Pegas, Commentaria ..., IV, ad. 1,35, gl. 10, n 24, citando textos de autoridade (Tiraquellus, De nobilitate, cap. 3; Escobar, De puritate sanguinis, p. 2, q. 1, gl. 4); cf. também Pegas, ibid., VII, ad. 1, 90, gl. 8, n 1 (“ex divitiis nobilitas creatur").

${ }^{22}$ Santo Tomás, op. cit., 2-2, q. 188, 7c.
} 
Por outro lado, apresenta sinais contraditórios. Para além de um sinal de benevolência de Deus, é, em termos puramente humanos, um fator de estabilidade, pois liberta os homens de apuros materiais, facilitando a retidão e evitando a corrupção a que os pobres são atreitos. Dá claridade e lustre à nobreza, permitindo que viva com esplendor e sem sordidez. ${ }^{23}$

Em suma, a riqueza pode constituir um meio legítimo de mudança de estado, se ela mesma não resultar de um processo ilegítimo de aquisição de bens. Por isto, em vez de legitimar a mobilidade social, a riqueza carece, pelo contrário, ela própria, de legitimação. Em si mesma, não garante a justiça da hierarquia social ocupada; antes, necessita da legitimação da justiça (nas formas e nos tempos da sua aquisição) para poder ser reconhecida.

Manuel Álvares Pegas, o já citado jurista português de seiscentos, discute esta problemática relação entre riqueza e justiça, a propósito da questão de saber se os ricos devem preferir os pobres nos cargos e nas honras públicos. $\mathrm{O}$ aspecto central é o de saber se a riqueza é presunção de virtude, sobretudo, de aptidão para fazer justiça, o dever primeiro do magistrado.

Os ricos - explica - oferecem em geral confiança, considerando-se que não cometem pecado, nem traição, nem mal algum. [Um passo do Digesto] aconselha, de forma elegante, a que não se elejam pobres como magistrados; pois, como ensina Ulpiano, para as honras [cargos] públicas [os pobres] não são iguais aos [ricos], uma vez que dificilmente se podem sustentar do seu. Assim, não é de modo algum útil ou honesto eleger magistrados desta qualidade, sobretudo quando haja quem tenha convenientes fortuna e público esplendor. Também se requer que não tenham necessidades, pois os que as experimentam não podem dispor de tempo para o exame diligente e necessário da justiça. ${ }^{24}$

Além do mais, "os pobres são facilmente corrompidos pelo negócio [das influências] (...) E, por isso, tornam-se suspeitos (...). O que faz com que freqüentemente os homens muito pobres feitos magistrados se tornem venais". 25 Este discurso a favor da riqueza como qualidade dos magistrados - a que se acrescenta a consideração de que "sem as riquezas a dignidade das famílias se torna pouco, conservando-se com elas o decoro e a honra" 26 - culmina com a conclusão de que "para as honras [ofícios e dignidades da república], os ricos

${ }^{23}$ M. A. Pegas, Commentaria..., I, ad. 1,1, gl. 19, n. 2-7; ibid., IV ad. 1,35, gl. 10, n 22 (“de vituperio et laudes divitiarum").

${ }^{24}$ Idem, IV ad. 1,35, gl. 10, n 18 ss.

${ }^{25}$ Ibid., n. 19.

${ }^{26}$ Ibidem, n. 20. 
são de preferir aos pobres". Contudo, não deixa de se apresentar a outra face da avaliação moral da riqueza:

No entanto, também, a partir de outros exemplos das vantagens da pobreza e dos inconvenientes da riqueza, se mostra que os pobres não devem ser excluídos das magistraturas e ofícios. E, inclusivamente, que não é de atender à riqueza nas eleições. ${ }^{27}$

Deste breve excurso resulta que a mobilidade social natural é, antes de tudo, a mobilidade que não fere a natureza das coisas, a honestidade; que não é falsa, fundada em títulos obtidos por burlas ou enganos; que não é artificial, "voluntária", contrária aos processos estabelecidos e devidos; que não é desordenada, introduzindo o caos ou a disformidade na sociedade; que, enfim, se faz no âmbito da ordem e dos processos nela inscritos para a sua própria modificação. Só esta configura a verdadeira mobilidade: pelo contrário, a outra, a "desordenada", a desonesta, a injusta, configura descalabro, revolução ou comoção, que necessitam ser corrigidas.

\section{Justiça}

Restabelecendo a honestidade está a justiça. Daí que as classificações sociais e os processos de mudança entre elas sejam matéria de justiça e de direito. A sua definição, construção e regulação eram então obra do direito. Não da lei positiva, mas da lei da natureza. Não de um direito voluntário, mas de mecanismos jurídicos objetivos inscritos na ordem das coisas. Tal lei e tal ordem eram, por sua vez, investigáveis por esse saber, cujo objeto era, justamente, o de escutar a natureza das coisas (a iurisprudentia - tinha deixado escrito Ulpiano no Digesto ${ }^{28}$ - est divinarum, atque humanarum rerum notitia).

Assim, a taxionomia social é, antes de tudo, uma taxionomia jurídica, ou seja, juridicamente regulada, determinando, o direito, os efeitos de cada status, assim como as causas da sua aquisição ou perda.

Diga-se, todavia, que esta atividade classificadora do direito e dos seus "sacerdotes" não nasce de uma livre e autônoma imaginação social por parte dos juristas. Como vimos, o discurso jurídico é variavelmente aberto ao contexto social e às suas imagens.

${ }^{27}$ Ibidem, n. 23. A este propósito, cita Navarrete, Conservação de monarchias, disc. 28; Bento Pereira, Librum Problematum, cui inscribebat Pallas togata, \& armata, Eborae, 1636, 12, p. 137.

${ }^{28}$ Ulpiano, Digesto, D., 1,1,10,2. 
Neste caso das classificações sociais, os juristas trabalham sobre informações que lhes chegam do exterior do direito. Do mundo físico-biológico recebem dados sobre as particularidades biológicas dos sexos, sobre a idade, sobre os lugares (de nascimento). Do senso comum, recebem classificações múltiplas que incorporam quase diretamente no seu discurso, mediante conceitos como os de fama, de usus, de mores. Do mundo da decisão política, cobram também fatos progressivamente mais relevantes, na medida em que a capacidade classificadora do monarca se vai impondo, como uma outra natureza criada por via da graça. Quero dizer que, ainda que a ordem dos estados sociais seja recortada com auxílio de categorias jurídicas e que os efeitos deste recorte sejam produzidos pelo direito, este recebe de distintos contextos não jurídicos informações relevantes, com que os resultados do labor classificativo do direito obtêm uma fácil caução social.

No entanto, para além de uma natureza jurídica, as taxinomias sociais têm, como dissemos, uma origem jurisprudencial, ou seja, não são apenas coisas de legisladores, são coisas sobretudo de doutores, de doutores em direito, autores de livros de teoria e, muitas vezes, de obras de grande impacto prático também. Esta origem jurisprudencial das classificações ou taxionomias sociais é um fato de primeira importância.

Em primeiro lugar, pela particular eficácia social que lhes confere esta particularidade de constituir clarificações jurídicas, ou seja, de ganharem efeitos de direito. Não é que a coercibilidade do direito fosse uma realidade massiva actual na sociedade de Antigo Regime (tal como não o é hoje em dia). Pontos de vista recentes, de historiadores e sociólogos, sublinham justamente o caráter marginal do direito, enquanto ordem coerciva, nesta sociedade. Ainda assim, a coercibilidade dos efeitos de direito, mesmo como horizonte apenas virtual, promove a sua aceitação social espontânea - i.e., independentemente da possibilidade ou da vontade dos poderes de levar por diante a sua imposição coativa.

Em segundo lugar, o estatuto discursivo dos textos jurídicos fomenta enormemente a sua disseminação social, pois as fórmulas jurisprudenciais traduzem, de forma compactada e aforística, compreensões (teológicas, filosóficas, éticas) muito elaboradas sobre a sociedade. Provêem normas e esquemas classificadores claros e nítidos, usados por juristas e por leigos, na sua versão original ou na sua forma vulgarizada, mesmo popular.

Finalmente, porque os esquemas classificatórios de natureza jurídica são atuados com um forte envolvimento cerimonial e litúrgico que aumenta o seu impacto "educador". ${ }^{29}$

29 "Inculcador", P. Bourdieu. 
O caráter jurídico destas classificações tem ainda importância inclusive num outro plano, ou seja, enquanto atribui competências privativas a certos atores sociais - os juristas - para gerirem as taxinomias. A declaração destas categorias e a sua aplicação concreta cabem, então, a entidades determinadas, não dependendo difusamente da fama pública (vox populi, ainda que esta possa ser um dos critérios relevantes para determinar o status de uma pessoa) nem das decisões arbitrárias do centro político. Não é excessivo insistir no alcance político deste fato, que explica a centralidade das decisões judiciais (e, por isto, da litigância em tribunal) na constituição das hierarquias sociais.

Uma questão suplementar é a de saber de que lógica classificativa são os juristas subsidiários ao efetuarem estas distinções de categorias sociais.

Ainda que uma leitura funcionalista - que tende a ver nelas expedientes para organizar o domínio social de uns grupos sobre outros - seja a mais comum na historiografia atual, suspenderemos aqui a referência a uma lógica "social", mantendo-nos, como se verá, de acordo com a descrição de uma lógica quase exclusivamente "textual". As concessões que faremos a uma sociologia mais clássica (i.e., mais dominada pelas determinações extratextuais) são unicamente duas. De um lado, salientar as vantagens do poder social que advém aos juristas (em face da sociedade e da coroa) do fato de as classificações doutrinais terem a primazia sobre as classificações legais. De outro lado, chamar a atenção para a importância que tem o fato de as classificações sociais se fundarem em critérios doutrinais, logo fluidos e mutantes, e não em critérios estritamente legais (logo fixos e estáticos). Por exemplo, quando a doutrina remete para o senso comum - como no caso da definição da nobreza fundada na publica aestimatio, a reputação pública -, as classificações doutrinais abrem-se às classificações "vividas".

\section{A mudança}

A sociedade de estados não é uma sociedade de castas. Os equilíbrios estabelecidos podem evolucionar. Esta (limitada) dinâmica - a que chamaríamos "mobilidade social" - era imputável ou a um automovimento da natureza, fecundado pelo tempo, ou às obras dos agentes.

\section{Ordem e tempo}

O transcurso do tempo tem, no mundo da política e do direito da sociedade de Antigo Regime, um poder constitutivo hoje desconhecido. 
O tempo constituía (como no caso do costume) ou reforçava (como no caso da firmatio legis) o direito. Enraizava situações jurídicas com uma força semelhante à da sentença e seguramente maior do que o documento. Fazia com que se ganhassem bens, por meio do seu uso diuturno; ou que se perdessem por não se protestar contra um tal uso por parte de outros. Inutilizava direitos a prestações ou a meios de defesa jurídica. E tudo isto com uma eficácia e uma amplitude que nos resultam hoje surpreendentes.

Esta eficácia jurídica do tempo tem a ver com as representações de então sobre a forma pela qual se manifesta a natureza. De novo, recorremos a S. Tomás para uma explicitação de imagens comuns, translatícias e pervasivas nestes séculos. Ao falar da natureza das criaturas livres, o teólogo, amparado em Aristóteles, distingue entre as disposições temporárias e as qualidades, a que chama hábitos, "que não se modificam facilmente, por terem causas imóveis". ${ }^{30}$ Estes hábitos, "que importam alguma diuturnidade", ${ }^{31}$ relacionam-se diretamente com a natureza, ou porque se amoldam ao seu estado atual, ou porque manifestam a tendência do ser para buscar os seus fins naturais. ${ }^{32} \mathrm{Se}$ alguns hábitos foram infundidos diretamente por Deus, ${ }^{33}$ outros, em contrapartida, são adquiridos. De fato, pela prática de atos múltiplos e diuturnos, os seres livres podem ganhar qualidades suplementares, as quais, mesmo não podendo contradizer a sua natureza primeira, a desenvolvem. ${ }^{34}$

Esta idéia de que os seres livres têm uma natureza mutável que, ao mesmo tempo, se manifesta (natureza atual) e se desenvolve (natureza potencial) por atos contínuos no tempo explica a importância que o tempo tem na constituição da ordem jurídica e política.

De fato, se uma prática se repete ao longo dos anos, isto não somente manifesta uma vontade tácita dos atores neste sentido, mas manifesta e institui neles disposições naturais (habitus) correspondentes. E, dado o otimismo ontológico que caracteriza esta mundividência, é assumido que estas disposições sociais ou individuais se amoldam aos equilíbrios mais racionais, mais justos, da sociedade.

Esta é a justificação profunda da eficácia constitutiva da "posse de estado" nas mudanças de situação jurídica das pessoas. A reputação contínua,

\footnotetext{
${ }^{30}$ Santo Tomás, op. cit., 1-1, q. 49, a. 2 e 3.

${ }^{31}$ Idem.

${ }^{32}$ Ibid., 1-1, q. 49, a. 3, resp.

${ }^{33}$ Infusi: Ibidem, 1-1, q. 51, a. 4.

${ }^{34}$ Ibidem, 1-1, q. 51, a. 2.
} 
pública e inveterada de pertencer a certo estado, ainda que infundada, institui como que uma segunda natureza que se acrescenta, desenvolve e apaga a prístina. Portanto, para fazer a prova de estado, não há que certificar um estado original ou essencial, bastando comprovar esta natureza "exterior" e "superveniente" construída pela reputação diuturna e durável.

É este conceito de mutabilidade da natureza - que distingue os estados das castas - que marca decisivamente as matrizes intelectuais de compreensão da "mudança social”. Não há mobilidade legítima (autêntica, honesta) que não obedeça a este modelo de desenvolvimento da natureza pelo tempo. Natureza e tempo são, assim, os progenitores da mobilidade social. Mas, na medida em que a nova natureza engendrada pelo tempo é também e ainda natureza, a sociedade muda, ficando igual. Então, a aparente mobilidade social é concebida, ao final, como estabilidade social, a mesma estabilidade que caracteriza a sempre mutável natureza do mundo físico ou astral. A "evolução" é "revolução", mas no sentido original de volta ao mesmo ponto.

Este ponto é bem ilustrado na aquisição da nobreza, em que a fama prescripta constitui o melhor título. "Grande jurisdição" - escreve, na segunda metade do século XVII, o jurista português João Pinto Ribeiro ${ }^{35}$ - "tem o tempo sobre a estima, \& reputação da nobreza". De fato, nesta sociedade em que a aparência manifestava a essência e em que a natureza se lia na tradição, a nobreza interior não podia deixar de manifestar-se exteriormente, desde que se deixasse passar um tempo suficiente. Como no domínio da religião, a justificação de um estado de nobreza interior não podia se fazer com puras disposições interiores (nobilitas probatur per actus, qui faciunt veram disctintionem inter nobilem et plebeum ${ }^{36}$ [a nobreza prova-se por atos que fazem o nobre diferente do plebeu]). Em contrapartida, ela deveria exprimir-se por atos repetidos ao longo da vida (nobilitas non nascitur in ictu oculi ${ }^{37}$ [a nobreza não nasce num piscar de olhos]). Só esta prática diuturna de um viver nobre poderia criar esta pública estimação de nobreza que, segundo Melchior Phaebus, é o critério-chave para distinguir os nobres (insuper nobilitas consistit in hominun existimatione [a nobreza consiste sobretudo na avaliação dos homens].). ${ }^{38}$

\footnotetext{
35 João Pinto Ribeiro, Sobre os títulos de nobreza de Portugal e os seus privilégios, em Obras varias, Lisboa, 1730.

${ }^{36}$ Melchior Phaebus, Decisiones senatus regni Lusitania (...), Lisbonæ, 1619 (ed. cons. 1760), I, d. $106, \mathrm{n}^{\circ} 35$.

${ }^{37}$ Baptista Fragoso, Regimen reipublicae christianae, Collonia Allobrogum, 1641-1652, I, 1. 3, disp. 6, $\mathrm{n}^{\circ} 198$ [n $\left.{ }^{\circ} 7\right]$.

${ }^{38}$ Melchior Phaebus, Decisiones senatus regni Lusitania (...), op. cit., d. 106, $\mathrm{n}^{\circ} 35$.
} 


\section{Obras}

O exemplo da nobreza servirá ainda para discutir outra via de aquisição ou perda de status, esta dependente da vontade própria - as obras.

As Ordenações afonsinas portuguesas (1446) definem assim os três principais estados da sociedade:

defensores são um dos três estados que Deus quis per que se mantivesse o mundo, ca assi como os que rogam pelo povo chamam oradores, e aos que lavram a terra, per que os homens hão de viver e se mantêm são ditos mantenedores, e os que hão de defender são chamados defensores.

Fica claro que a classificação se funda na diversidade de funções sociais dos agentes, ainda que este distinto desempenho de funções não derive das vontades pessoais, mas tenha a ver com as qualidades e as virtudes naturais de cada um.

Assim como tantas outras distinções entre as coisas, a nobreza, por exemplo, derivaria da própria ordem. Esta teria dado a umas coisas a primazia sobre as outras, em razão da sua utilidade ou da sua beleza (ratione utilitatis vel pulchritudinis): "Em todas as coisas bem regidas, \& governadas, há-de haver esta ordem: que isto é o que a natureza principalmente em si contém". ${ }^{39}$ Daí que a nobreza seja, portanto e em princípio, um estado natural que residiria inclusivamente nas coisas inanimadas (ouro, pedras preciosas), ou nos animais carentes de razão (falcão, boi, leão) ou mesmo nas qualidades (como as cores). ${ }^{40}$

Nos homens, como nas coisas da natureza, esta nobreza natural derivaria da virtude, sobretudo daquela virtude que torna alguém ou alguma coisa apta a dominar. ${ }^{41}$ Como dirá Bártolo (citado por Juan de Otalora) ${ }^{42}$ reside "no hábito electivo [i.e., na habituação de bem decidir] acerca das coisas que respeitam à preeminência e ao domínio". Neste sentido, a nobreza refere-se à posse de certas qualidades espirituais, que, também em princípio, ou se adquirem pelo

\footnotetext{
${ }^{39}$ Álvaro Ferreira de Vera, Origen da nobreza politica (...), Lisboa, 1631, p. 3.

${ }^{40}$ Hermann Wissman, De iure circa colores, Lipsiae, 1683.

${ }^{41}$ Aristóteles, Politica, IX; Etica, IV.

${ }^{42}$ Juan Arce e Otalora, Summam nobilitatis Hispaniae, छ̈ immunitatis regiorum tributorum causas, jus (...), Granatae, 1553, 15 v.
} 
sangue, ou, pelo menos, se enraízam por tradição familiar; reside nos genes, reproduzindo-se como as características naturais das pessoas. E, por isto, seria também irrenunciável e indisponível, pois ninguém poderia fugir ou dispor da sua própria natureza.

Porém - e chegamos com isto ao ponto mais interessante - existia uma outra nobreza, mais exterior e mais aleatória (por assim dizer), ganha por obras, correspondente ao exercício de certas funções ou ofícios da república.

Os tratadistas chamam-lhe, por oposição à anterior, nobreza políti$\mathrm{ca},{ }^{43}$ pois deriva não da natureza, mas de normas de direito positivo, como os costumes da cidade. ${ }^{44}$ Deste tipo é a nobreza que se adquire: a) pela ciência (doutores, licenciados, mestres de artes, bacharéis; ${ }^{45}$ b) pela milícia "armada" (cavaleiros de ordens militares, oficiais militares (condestável, almirante, capitães-mores, capitães de fortalezas, cavaleiros de companhias de cavalos, capitães e alferes de ordenanças); c) pela "milícia inerme"; ${ }^{46}$ d) pelo exercício de certos ofícios: governos de armas das províncias ${ }^{47}$ presidentes dos tribunais de justiça da corte; conselheiros régios; ${ }^{48}$ chanceler-mor; ${ }^{49}$ juízes das chancelarias e audiências; ${ }^{50}$ corregedores $;{ }^{51}$ provedores $;{ }^{52}$ juízes régios $;{ }^{53}$ juízes ordinários, vereadores, almotacés e alguazis, procuradores dos concelhos, meirinhos e alcaides; ${ }^{54}$ mas só nas terras em que fosse costume reservar este lugar a nobres.

\footnotetext{
${ }^{43}$ João de Carvalho, Novus et methodicus tractatus de una, et altera quarta deducenda, vel non legitima, falcidia, et trebellianica (...), Colloniae Allobrogum, 1634 (ed. cons., 1746), nº 200 ss.; Pascoal de Melo Freire, Institutiones iuris civilis lusitani, Conimbricae, 1789, I, 3; Manuel de Almeida e Sousa Lobão, Notas a Melo, Lisboa, 1828-1829, 56; sobre o tema, António Manuel Hespanha, “A nobreza nos tratados jurídicos dos sécs. XVI e XVII", Penélope, 12(1993), 27-42.

${ }^{44}$ João de Carvalho, Novus et methodicus..., op. cit., n ${ }^{\circ} 264$ ss.

${ }^{45}$ Idem, n ${ }^{0} 283$ ss.

${ }^{46}$ Ibid., 362 ss.: oficiais palatinos - v.g., mordomo-mor, camareiro-mor, moços da câmara, trinchante-mor, estribeiro-mor, capitães da guarda e dos ginetes; membros do Conselho de Estado, notários régios, secretários régios, oficiais da fazenda.

${ }^{47}$ Ibidem., n. 405.

${ }^{48}$ Ibidem, n. 412.

${ }^{49}$ Ibidem, n. 413.

${ }^{50}$ Ibidem, n. 421.

${ }^{51}$ Ibidem, $\mathrm{n}^{\text {os }}$ 424-425.

${ }^{52}$ Ibidem, n. 426.

${ }^{53}$ Ibidem, n. 428 ss.

${ }^{54}$ Ibidem, ${ }^{\text {os }} 432-442,445$.
} 
Neste caso, o título aquisitivo de nobreza não é nem a natureza prístina, nem a natureza adquirida pelo largo curso do tempo, mas a vontade de promoção expressa em obras adequadas ou eficazes para a mudança de estado.

Entre estas obras estão o desempenho de ofícios militares (militia armata) ou curiais (militia inerme). Mas estão também o estudo que leva à ciência ou, ainda que de forma mais problemática, o negócio que leva à riqueza.

No que toca à ciência, era comum a opinião de que produzia nobreza. São conhecidos os louvores da ciência e do estudo contidos na tradição literária da Europa tradicional. As Escrituras definem a ciência como coisa de Deus. ${ }^{55}$ Os filósofos, por sua vez, antepunham a ciência ao culto da virtude. ${ }^{56}$ Enquanto os Pais da Igreja descreviam o iter que levava da ciência à beatitude e a Deus. ${ }^{57}$ Assim, o estudo não pode ser senão uma atividade moralmente benéfica, que torna a alma solícita para a honestidade: Labor scholastiqus otium non est, sed negotium et quod animus reddit ad honestatem solicitu, escreve Sêneca, nas Cartas. A conclusão de que o estudo e a ciência produzem nobreza é conseqüência natural. ${ }^{58}$ Scientia homines nobiles facit, escreve o jurista Pegas, ${ }^{59}$ "donde se deduz que o bacharel goza de nobreza". ${ }^{60}$

Também por obras se podia perder a nobreza. Os fundamentos da perda da nobreza eram o reflexo, em negativo, dos fundamentos da sua aquisição. Assim, a nobreza perdia-se por fatos que infirmassem a presunção de virtude, que produzissem a infâmia (como a prática do crime de lesa-majestade) ou que prejudicassem a reputação pública (como o exercício do comércio sórdido ou de profissão vil).

Quanto à riqueza, existia o testemunho favorável de Aristóteles, que fazia equivaler a nobreza à fortuna antiga ([divitia] nihil aliud est quam inveteratae divitiae $;{ }^{61}$ [est] acquisita ex propria industria, vel divitis). ${ }^{62}$ Mas é claro que, para

\footnotetext{
${ }_{55}$ Scientia pro divinae cognitione, 2, Cor., vers. 6; scientiarum dominus est Deus, I, Salm., 2, vers. 3 .

${ }^{56}$ Procedit scientia, virtutis qultum, Aristóteles, Politica, lib. 3.

${ }^{57}$ Via ad Deum est scientia, quae ad institutionem recte et honeste vivendi pertinet. Est disciplinae bonitas et beatitudo. Per scientiam igitur ad disciplinam, per disciplinam ad bonitatem, per bonitatem ad beatitudinem, Hugo de S. Vítor, De instructione novitiorum.

${ }^{58}$ Aristóteles, De anima, 1; Politica, 4,4. Fontes jurídicas: l. providendum, C. de postulando (Fragoso, 1601, I, 1. 3, disp. 6, n 149).

${ }^{59}$ M. A. Pegas, Commentaria, op. cit., IV, ad I, 35, gl. 8, nº 3 .

${ }^{60}$ Ibid., VII, ad I, 90, gl. 4, n 9.

${ }^{61}$ Melchior Phaebus, Decisiones senatus regni Lusitania (...), Lisbonæ, op. cit., I, d. 14, no 8.

${ }^{62}$ Ibid., I, d. 14, nº 20.
} 
uma parte dos autores, a proposição não era evidente. A afirmativa fundavase antes num realismo sociológico, na observação das leis da vida (nobilitas plerumque consistit in divitis), ${ }^{63}$ sobretudo dadas as dificuldades de levar uma vida à maneira da nobreza sem 0 apoio da fortuna. ${ }^{64}$

As obras são, portanto, os complementos indispensáveis de uma vontade de mudar, tal como, no plano sobrenatural, são o complemento indispensável da fé. A pura vontade, como a pura fé, são incapazes de produzir resultados. Mas, inclusivamente, o tipo de obras eficazes para produzir a mudança de estado é definido não pelo agente, mas pela natureza das coisas.

\section{Graça: gratidão, liberalidade e misericórdia}

Neste mundo social indisponível, ossificado e de mudanças lentas e prefixadas, a mobilidade social não podia resultar nem da vontade, nem de mudanças instantâneas. Só o tempo, a vontade traduzida em obras adequadas e a riqueza honestamente adquirida podiam modificar a ordem social estabelecida e prescrita, quando podiam.

No entanto, existia a possibilidade de mudanças dramáticas, não inscritas na ordem do mundo, alterando prodigiosamente os equilíbrios estabelecidos, provenientes de manifestações livres da vontade. Como milagres, semelhantes àqueles pelos quais Cristo mudara a água em vinho ou ressuscitara Lázaro.

Esta irrupção gratuita e absoluta da vontade ordenadora na ordem criada era a graça. A graça é o domínio de afirmação da vontade, pela qual se criam, espontânea e arbitrariamente, situações novas, a saber, se transmitem bens ou se outorgam estados.

Num mundo concebido como estando sujeito a uma ordem constitucional, os atos gratuitos têm que ser considerados como coisa rara e excepcional. ${ }^{65}$ Sobretudo se alteram substancialmente o estado das pessoas ou a distribuição dos bens e das vantagens, operando mudanças dos equilíbrios sociais equiparáveis, no plano da natureza, aos milagres de Deus. Estes milagres de engenharia social e política, quando não cabem a Deus, cabem aos seus vi-

\footnotetext{
${ }^{63}$ Jorge de Cabedo, Practicarum observationum sive decisionum Supremi Senatus regni Lusitaniae, Olyssipone 1602-1604, 2 vols. (ult ${ }^{\mathrm{a}}$ ed. 1734), I, dec. 73, nº 5.

64 "Nobilitas sine divitis sordescit", Barbosa, Remissiones doctorun (...), ad. V, 139, $\mathrm{n}^{\circ}$ 7; sobre o tema, v. Álvaro Ferreira de Vera, Origen da nobreza politica (...), op. cit., p. 349 ss.

${ }^{65}$ Por isto, as doações entre particulares, superiores a certa quantia, deviam ser confirmadas pelo rei (insinuação).
} 
gários no mundo - os reis, cuja graça é um aspecto menos recordado das suas capacidades taumatúrgicas. Por meio da graça, eles operam autênticos milagres sociais e políticos: legitimam filhos bastardos, enobrecem peões, emancipam filhos, perdoam criminosos, atribuem bens e recursos.

A importância e a generalidade dos mecanismos de graça justificam que nos detenhamos um pouco na sua teoria subjacente.

O núcleo duro das virtudes morais é constituído pela justiça, ${ }^{66}$ a disposição para "atribuir a cada um o seu", realizando e mantendo a ordem. Todavia, alguns deveres, apesar de não poderem ser configurados como de justiça, contribuem igualmente para a manutenção da ordem.

Tais são, por exemplo, os deveres de gratidão. Aqui, não existiria uma ação jurídica pela qual se demandasse alguém para "que recompense outrem pelo que este lhe fez" ${ }^{67} \mathrm{Nem}$ por isto seria menor a exigência, pois a não satisfação do débito (apesar de não tutelado legalmente) subverteria a honestidade dos costumes. É isto que explica a firmeza que têm as expectativas de retribuições (ou remunerações) por parte dos que prestam favores (benfeitores ou benemerentes).

O caso típico de cumprimento de deveres de gratidão na sociedade de Antigo Regime é o das mercês régias, remuneratórias dos serviços dos vassalos. Estes serviços não eram estritamente devidos, importando alguma componente graciosa, algum favor, que constituía o beneficiário em gratidão. A mercê era, então, o pagamento do dever de gratidão, um dever não estritamente legal, mas quase-jurídico (antidoral, para utilizar a palavra grega que exprime esta fortíssima obrigação). ${ }^{68}$ Esta extrema proximidade com a justiça autorizava que se utilizasse a palavra ação para descrever o quase-direito dos clientes (maxime, os vassalos do rei que lhe tivessem prestado serviços) às mercês. Na generalidade dos juristas, estes deveres de doação (mas de doação remuneratória) de mercês são mesmo considerados como estritos deveres de justiça comutativa (ou seja, da justiça que exige que a uma prestação corresponda outra, equivalente e inversa) e, portanto, deveres jurídicos em sentido estrito. ${ }^{69}$

\footnotetext{
${ }^{66}$ Santo Tomás, op. cit., 1-1, qq. 57-122.

${ }^{67}$ Ibidem, q. 80, a. un., resp.

${ }^{68}$ Bartolomé Clavero (1991), Antidora. Antropología católica da economía moderna, Milano, Giuffrè, 1991.

${ }^{69}$ Um outro caso típico de dever de gratidão é, para o mutuante, o de pagar os juros da quantia mutuada, no caso de mútuo oneroso (ou usura) (cf. Clavero, Antidora..., op. cit.).
} 
O jogo conjunto destes fortíssimos deveres explica bem a estrutura quase jurídica das relações de hierarquia na sociedade de Antigo Regime. Ao superior (praestans) - pai, senhor, etc. - deve-se-lhe continuamente (ainda que não legalmente), veneração, expressa em piedade e obséquios (dos filhos em relação aos pais), auxilio e conselho (dos clientes em relação aos patronos). Como a satisfação destes deveres não legais e, portanto, não exigíveis importa alguma gratuidade (algum favor), aos inferiores que os tenham cumprido deve-se-lhes o afeto (affectus) da gratidão (expressa nos efeitos [effectus] das mercês).

Ainda menos exigíveis do que os deveres de gratidão eram aqueles cujo não cumprimento não ofendesse radicalmente os bons costumes (e.g., os deveres que derivavam da liberalidade, da afabilidade ou da amizade). O seu caráter menos devido faria com que, aqui, se pudesse falar de natureza gratuita da prestação e afirmar, portanto, que "pouco eram devidos" (parum habent de rationem debiti, Santo Tomás, Sum. theol., ibid:: "O que não é dado por mérito do precedente, é dado grátis. A graça exclui a razão de débito". ${ }^{70}$ Estão compreendidos nesta classe os deveres de liberalidade, de amizade, de caridade ou de magnanimidade, ou seja, em termos mais gerais, a graça. Dependente mais de uma disposição liberal do que de uma necessidade de cumprir um dever estrito, a graça constituía, no entanto, um dever, por ser exigido, nuns casos mais, em outros menos, por situações (ou relações) objetivas em que as pessoas se encontram. Os amigos devem-se graças (liberalidades, favores) mútuas; os poderosos devem proteção aos humildes (amizade, liberalidade). Os ricos devem esmola aos pobres (caridade). E alguns - como o rei - pela especial dignidade em que estão colocados, devem tudo isto numa forma superlativa (magnanimidade).

Embora não se trate de deveres jurídicos nem de deveres tão estritos como os da religião, da piedade familiar ou da gratidão, não se trata menos de deveres, de vínculos derivados da natureza do homem e das relações sociais. Neste sentido, alguns autores aproximam os deveres de graça da justiça distributiva ("a qual é galardoar e remunerar cada um, segundo o que merece, da qual justiça é muito próprio dos reis usar", Privilégio de João I de Castela [1444]). ${ }^{71}$

\footnotetext{
${ }^{70}$ Santo Tomás, op. cit., 1-1, q. 111, 1 ad. 2.

${ }^{71}$ Salustiano de Deus, Graça, merced e patronazgo real. A Camera de Castilla entre 1474-1530, Madrid, C.E.C., 1994, 103.
} 
A teoria da graça prova, de novo, as limitações da idéia de mudança social na sociedade moderna. A aquisição de novos estados - seja pela nobilitação, seja por acréscimos patrimoniais devidos a mercês, seja pela extinção de diminuições estatutárias, como a menoridade ou a condenação criminal - era considerada como um mero reconhecimento de situações devidas (ainda que não legalmente ou em justiça), como um retorno à ordem momentaneamente olvidada ou ofendida, ou, talvez melhor, a graça consistiria no aperfeiçoamento da antiga ordem por uma outra de nível superior. A mudança convertendo-se, assim, numa retificação ou numa reconstituição.

A graça não representa, então, uma irrupção absolutamente arbitrária da vontade no domínio dos equilíbrios sociais. Ao revés, a graça realiza também, à sua maneira, a ordem. A mobilidade social que desencadeia é apenas aparente. No fundo, a nova posição atribuída ao agraciado já lhe era devida, ainda que não juridicamente. Esta proximidade em relação à justiça é tão forte que, para se traduzir a pretensão do postulante a uma graça ou mercê, se fala precisamente de ação.

A eficácia - decisiva, mas limitada - da graça na constituição de estados também é discutida a propósito da aquisição da nobreza por rescrito régio.

Para Baptista Fragoso, que escreve em Portugal em finais do século XVI, a nobreza concedida pelo príncipe não deixa de constituir, por oposição à nobreza interior, natural, uma "nobreza extrínseca". É a "qualidade atribuída por quem detém o principado, em virtude da qual aquele que a recebe é assinalado como superior ao plebeu" "[2 [nobilitas extrinseca est qualitas illata per principatum possidentem, que quis acceptus ostenditur ultra honestos plebeios]).

De fato, esta independência da qualidade de nobre em relação a um ato de graça régia refletia a idéia de que a hierarquia das pessoas consiste numa disposição da natureza, na existência de uma ordem natural e não num fato da vontade política.A vontade política não podia senão declará-la, concedê-la expressamente (ratificá-la) a quem já a têm implicitamente (a "quem a merece"), como que de raiz.

[A nobreza] - ensina Álvaro Ferreira de Vera - é uma qualidade concedida por qualquer príncipe àquele que a merece, ou porque descende de pessoas que a mereceram por serviços feitos à República, assim nas armas, como nas letras; ou por se ter avantajado aos mais em qualquer memorável exercício. ${ }^{73}$

${ }^{72}$ Baptista Fragoso, Regimen reipublicae christianae, cit., I, 1.3, disp. 6, p. 316, n ${ }^{\circ} 131$.

${ }^{73}$ Álvaro Ferreira de Vera, Origen da nobreza politica (...), op. cit., p. 5 ss. 
Ainda que este autor afirme que "os reis são os que concedem essencialmente a nobreza e fidalguia", ${ }^{74}$ as causas eficientes destas últimas são a virtude e a linhagem, sendo o rei somente a causa formal. ${ }^{75}$

No entanto, outros atribuem à ação do príncipe um caráter mais criador. Tal como Deus, ele seria a verdadeira causa eficiente da nobreza: "do mesmo modo que junto de Deus é nobre quem Deus pela sua graça torna grato ao mesmo Deus, assim no mundo é nobre quem o príncipe, por lei ou pela sua graça, faz grato ou nobre" (Bártolo, cit. por Otalora) ${ }^{76}$ Assim, o arbitrium principis não teria limites.

"A nobreza pertence só ao rei, sendo uma superioridade real e induzindo-se por concessão régia ou privilégio" (nobilitas ad solum Regem pertinet, Đest superioritatis regalis: §̊ nobilitas inducitur ex regis concessione, seu privilegio), afirmam Jorge de Cabedo, escrevendo em finais do século XVI ${ }^{77}$ e Melchior Febo, um pouco mais tardio. ${ }^{78}$ Entre esta nobreza dativa e a nobreza generativa não existiria nenhuma diferença. ${ }^{79}$ António Gama é ainda mais decisivo: ninguém adquire a nobreza por si mesmo, mas por dignidade de ofício ou por concessão real ${ }^{80}$ [(nemo acquiritur nobilitatem a seipso, sed a dignitate oficii, vel concessione regis)], ou seja, a idéia de que o príncipe tem a capacidade para decidir da nobreza, tanto ou mais que a natureza, está a tornar-se, progressivamente, comum ou, inclusivamente, dominante.

Em todo o caso, se se tratasse - não das categorias específicas de nobreza cortesã conhecidas das etiquetas palacianas ou protoburocráticas - mas da categoria geral de "nobre", tal como se encontrava nas fontes de direito comum, a doutrina requeria títulos de nobreza menos dependentes do favor real e mais próximos dos hábitos sociais, tais como "viver à maneira da nobreza" ou "a fama inveterada".

A misericordia é um tipo especial de graça suscitado pela tristeza que nos causa a situação daqueles (os miseráveis) ${ }^{81}$ a quem a fortuna ( $=0$ acaso, a desordem

\footnotetext{
${ }^{74}$ Idem, 6.

${ }^{75}$ Ibid.

${ }^{76}$ Juan Arce e Otalora, Summam nobilitatis Hispaniae, 8 immunitatis regiorum tributorum causas, jus (...), op. cit., fl. $17 \mathrm{v}$.

77 Jorge de Cabedo, Practicarum observationum (...), op. cit., I, dec. 73, nº 1.

${ }^{78}$ Melchior Phaebus, Decisiones senatus regni Lusitania (...), op. cit., I, d. 14.

${ }^{79}$ Ibid., n. 138.

${ }^{80}$ António da Gama Pereira, Decisionum Supremi Senatus..., Ulyssipone 1578 (ult ${ }^{\mathrm{a}}$. ed. 1735), dec. $86, \mathrm{n}^{\circ} 5$.

81 "Os miseráveis" - escreve o jurista português Manuel Álvares Pegas - "são aqueles cuja natureza nos move a sentir pena" (Commentaria ..., op. cit., XIII, ad. lib. 3, t. 5, gl. 5, cap. 6, n' 4: forasteiros, estrangeiros, cativos, saídos da cadeia, enfermos, comunidades, hospitais, agricultores, rústicos, meretrizes, expostos, mercadores em viagem; cf. Sórzano, lib. 2, cap. 28), pais de muitos filhos, universidades (ou corpos coletivos, em geral), estudantes.
} 
permitida pela ordem) tirou os seus direitos (o seu lugar natural na ordem). Esta tristeza - devida a que se não tem algo a que tende o apetite natural ${ }^{82}$ - é como que uma nostalgia da ordem que o acaso não deixou que se realizasse. A doação misericordiosa (também chamada esmola) é então uma espécie de doação liberal, caracterizada pelo seu específico impulso (ou seja, pelo desejo de aliviar a miséria alheia). ${ }^{83}$

Tal como a doação liberal, a esmola, atribuindo bens não devidos e, com isto, alterando os equilíbrios estabelecidos, não relaxa a justiça. De fato, "Deus" - como explica S. Tomas ${ }^{84}$ - "ao atuar misericordiosamente, não apaga a justiça, mas realiza a sua plenitude".

Apesar de todas as suas limitações, a graça - sobretudo a graça régia - constitui o principal mecanismo de mobilidade dramática e rápida, mas socialmente reconhecida, no Antigo Regime. Este fato determina a importância política da realeza nos processos sociais de mudança. A graça régia não é tão importante por ser uma fonte de benefícios - como o era também, v.g., o comércio - mas por ser uma fonte de legitimação social desses benefícios. Nos casos em que nem obras adequadas, nem tempo prescrito pudessem justificar a ascensão social, a graça do rei restava como único meio de coonestar a mudança de estado.

${ }^{82}$ Santo Tomás, op. cit., 2-2, q. 30, a. 1.

${ }^{83}$ Idem, 2-2, q. 31, 1c.

${ }^{84}$ São Tomás, op. cit., I, q. 31, a. 3. 